\title{
Chapter 6 \\ Impact of Fukushima Daiichi Accident \\ on Japan's Nuclear Fuel Cycle and Spent Fuel Management
}

\author{
Joonhong Ahn
}

\begin{abstract}
This chapter briefly summarizes the current status of spent nuclear fuel and historical development of nuclear fuel cycles in Japan, and problems that Japan faces after the Fukushima Daiichi nuclear accident for spent fuel management. (1) Aomori Prefecture's refusal to store HLW and spent fuel in Rokkasho without a plan for them to be taken out to a permanent geological repository, (2) drainage of national wealth for purchasing additional oil and gas, (3) international pressure on Japan not to have an unnecessary Pu stockpile, and (4) perpetual safeguards inspection and higher potential radiological risk to be imposed on a final repository for spent fuel and separated $\mathrm{Pu}$ and $\mathrm{U}$, are coupled to each other, creating a deadlocked situation after the accident.
\end{abstract}

Keywords Spent fuel management - Nuclear fuel cycle $\cdot$ Pu stockpile Phase-out • Post fukushima

\subsection{Status Quo}

Nuclear fuel before usage in a contemporary light-water reactor (LWR) is made of uranium oxide (UOX) consisting of the fissile U-235 isotope comprising $4.5 \%$ of total uranium (U) atoms. After producing 45,000 mega-watt-days of heat per metric ton $(\mathrm{MWd} / \mathrm{MT})$, the fuel is discharged from the reactor. This spent fuel still contains around $0.8 \%$ of $\mathrm{U}-235$ and $0.9 \%$ of plutonium $(\mathrm{Pu})$ (approximately $9 \mathrm{~kg}$ ), of which about $0.5 \%(5 \mathrm{~kg})$ is fissile. If one metric ton (MT) of spent fuel is reprocessed, $9 \mathrm{~kg}$ of $\mathrm{Pu}$ and approximately $960 \mathrm{~kg}$ of $\mathrm{U}$ are recovered separately,

\footnotetext{
J. Ahn $(\bowtie)$

Department of Nuclear Engineering, University of California,

Berkeley, CA 94720, USA

e-mail: joonhong.ahn@berkeley.edu
} 
Table 6.1 Japan's spent fuel balance $(02 / 2013)$

\begin{tabular}{l|r}
\hline Stored at JNFL in Rokkasho & $3,350 \mathrm{MT}$ \\
\hline Stored at nuclear power plants & $14,170 \mathrm{MT}$ \\
\hline Reprocessed in U.K. and France & $7,100 \mathrm{MT}$ \\
\hline Reprocessed at Tokai-mura & $1,020 \mathrm{MT}$ \\
\hline Total & $25,640 \mathrm{MT}$ \\
\hline
\end{tabular}

Table 6.2 Japanese plutonium stockpile $(\mathrm{kg})$ (as of the end of 2011) [1]

\begin{tabular}{l|l}
\hline in Japan (Pu fissile) & $9,295(6,316)$ \\
\hline Reprocessing plants & 4,364 \\
\hline MOX fuel plant & 3,363 \\
\hline Stored at reactors & 1,568 \\
\hline in Europe (Pu fissile) & $34,959(23,308)$ \\
\hline U.K. & 17,028 \\
\hline France & 17,931 \\
\hline Total (Pu fissile) & $44,254(31,837)$ \\
\hline
\end{tabular}

and the rest becomes vitrified high-level waste (HLW), including fission-product isotopes and minor actinide isotopes, such as neptunium, americium, and curium. The HLW is solidified with borosilicate glass in a stainless steel canister.

In the past 50 years of nuclear power utilization in Japan, 25,640 MT of spent nuclear fuel has been generated. Of this amount, 7,100 MT was reprocessed in France and U.K., and the plant in Tokai-mura currently owned by Japan Atomic Energy Agency (JAEA) reprocessed 1,020 MT (Table 6.1). As a result, Japan possesses approximately $44 \mathrm{MT}$ of plutonium $(\mathrm{Pu})$ (Table 6.2) and about 8,000 canisters of HLW. The un-reprocessed spent fuel $(25,640-1,020-7,100=17,52$ 0 MT) is stored either at each nuclear power plant in Japan (total 14,170 MT) or in the storage facility attached to the Rokkasho reprocessing plant (3,350 MT). 14,170 MT occupies approximately $70 \%$ of total storage capacity $(20,000 \mathrm{MT})$ in all existing nuclear power plant sites. 3,350 MT is already $97 \%$ of the spent fuel storage capacity at the Rokkasho reprocessing plant.

\subsection{How Has This Status Quo Been Generated?}

In 1955, 10 years after the end of World War II, Japan established the Atomic Energy Basic Law, and launched its nuclear development program. The Japanese national policy for nuclear fuel cycle was established during the 1970s and 1980s to achieve "energy independence" by decreasing dependence on oil, motivated by the experience of the oil crises in 1973 and 1979. The establishment of the nuclear fuel cycle, consisting of $\mathrm{U}$ enrichment, reprocessing of spent nuclear fuel to recover $\mathrm{Pu}$ and $\mathrm{U}$, and a fast breeder reactor (FBR), became the national policy with the highest priority. In 1988, Japan successfully reached a comprehensive Nuclear 
Cooperation Agreement (NCA) with the United States that allowed Japan to develop and own the nuclear fuel cycle. It was a remarkable diplomatic achievement in the international environment after the nuclear test by India in 1974, upon which the U.S. strengthened its anti-nuclear fuel cycle policy. Indeed, Japan is the only non nuclear weapons country ${ }^{1}$ that has industrial-scale capability of U enrichment, PUREX reprocessing, and FBRs, acknowledged by the international community, particularly by the U.S.

After reaching the U.S.-Japan NCA in 1988, Japan made steady progress toward construction of nuclear fuel cycle facilities. In 1992 the Japan Nuclear Fuel Industry (JNFI), a private company established by the utilities companies, started commercial operation of the first commercial U enrichment plant in Rokkasho, with the capacity of 150 MT Separative Work Unit/year. In 1989, the Japan Nuclear Fuel Services (JNFS), yet another company established by the utilities, submitted a license application for the first commercial reprocessing plant in Rokkasho, and in 1993, its construction began. ${ }^{2}$ JNFI and JNFS were later merged into Japan Nuclear Fuel Limited (JNFL). In 1995, an experimental FBR, Monju, started electricity supply to the grid. ${ }^{3}$

After the 1997 Kyoto Protocol ratified at the United Nations Framework Convention on Climate Change (UNFCCC), reduction of greenhouse-gas emissions was added as the main objective of nuclear power utilization. In other words, the 1997 Kyoto Protocol solidified the raison d'etre of Japan's nuclear energy industry, and this was the mindset in place until the Fukushima Daiichi accident on March 11, 2011. Prior to it, the nuclear community firmly believed that the fleet of nuclear reactors supported by the nuclear fuel cycle would grow and expand, that capacities for $\mathrm{U}$ enrichment and spent fuel reprocessing should be established, that $\mathrm{Pu}$ should be bred by FBRs, and so forth. The Japanese nuclear community had never conceived of "sudden braking" scenario as the situation currently observed in Japan that all reactors halted operation after the Fukushima Daiichi accident. The sudden braking clearly revealed that there was a serious oversight, or lack of plan B, in the national policy for development of the nuclear fuel cycle and for spent fuel management.

\subsection{What Are the Problems with the Current Situation?}

After March 11, 2011, all forty-eight operable nuclear reactors in Japan had been put out of service one after another due to previously scheduled regular maintenance and inspection, and none could resume operations except for the Number 3 and 4 reactors at Kansai Electric's Oi Nuclear Power Station for the term between

\footnotetext{
1 EURATOM consisting of EU countries has similar NCA with the U.S.

2 But as of 2014 the plant has not started its operation due to a series of technical troubles.

3 But soon after that it had the sodium leak accident, and stopped its operation since then until now.
} 
July 2012 and September 2013. Prime Minister Noda expressed his support for the restarting of Oi's two reactors on June 8, 2012, driven by the projection that the Kansai area, including Osaka, Kyoto, and Kobe, would otherwise suffer from a severe electricity shortage in the coming summer.

While the two units at Oi could restart for a year as an emergency measure, others could not, because more stringent regulations implemented after the accident require all existing 48 reactors to be back-fitted before they obtain permission to restart. Aged reactors in general need more work to comply with new regulations, which creates higher costs, but investing in aged reactors may not pay off if the remaining license term is not long enough. This would lead utilities companies to consider decommissioning their reactors before the license term ends, and thus almost certainly the total number of Japanese nuclear reactors will be reduced in the future. What is not so clear at this moment is how fast the reduction process will occur, and at what capacity the Japanese nuclear fleet size will level off.

The Japanese monthly trade statistics [2, 3] indicate that Japan's import of natural gas jumped from about 3 trillion yen in 2009 and 2010 to 5.4 trillion yen in 2011. Similarly, oil imports in 2011 increased to 12 trillion yen from 9 to 10 trillion yen in the previous years. Such hikes occurred because the gap created by loss of the nuclear reactor fleet had to be filled by the existing fleet of fossilfired plants. If this situation continues, Japan has to spend an extra 4-5 trillion yen every year. In addition, burning oil and gas emits carbon dioxide into the atmosphere. In 2011, Japan emitted an extra 175 million ton of carbon dioxide compared to the average annual emission before the accident. This pattern will continue as long as Japan relies fully on fossil fuels.

When Aomori Prefecture agreed in 1989 to build in Rokkasho the reprocessing plant and attached interim storage facilities for spent fuel and HLW canisters, the central government promised that Rokkasho would never be the final disposal site for HLW. After the accident, in the course of public discussions about whether nuclear power utilization should be continued or phased out and whether reprocessing should be carried out or abandoned, Aomori Prefecture warned that all spent fuel and HLW canisters currently stored in the Rokkasho site must be returned back to their original plants if reprocessing is not carried out in Rokkasho. In this case, 3,350 MT of spent fuel stored currently in Rokkasho and 8,000 canisters of HLW to be returned from U.K. and France would need to be relocated from Rokkasho.

In October 2013, in Mutsu city, Aomori, the interim storage facility for spent fuel became available first with a 3,000 MT capacity with a planned expansion to $5,000 \mathrm{MT}$ in the future. Considering that the fleet size is likely to be significantly reduced, and that there is a total of approximately 10,000 MT (6,000 in individual power plant sites and 3,000-5,000 in Mutsu) of available space for spent fuel storage, Japan can restart reactors for a decade or longer while postponing decision on reprocessing. This offers Japan an invaluable grace period to review policy, during which time a plan must be developed for the medium- and long-term range. 
The United States has been demanding that Japan make clear its plans for commercial $\mathrm{Pu}$ utilization to avoid creating a large $\mathrm{Pu}$ stockpile. However, with the onset of delays in the development of FBR technologies, the Atomic Energy Commission and utilities companies decided to introduce utilization of $\mathrm{Pu}$ in the form of mixed oxide (MOX) fuel with existing LWRs. 44 MT of separated Pu (Table 6.2) can be made into approximately 640 MT of MOX fuel at the MOX fuel fabrication plant to be commissioned in 2017 at JNFL's Rokkasho site with production capacity of $130 \mathrm{MT} / \mathrm{year}$. Thus, if LWRs can be restarted, the Pu stockpile can be burnt in LWRs in the form of MOX. Assurance of timely Pu consumption by MOX utilization will be helpful for the Rokkasho reprocessing plant to commence its operation. However, if an immediate nuclear phase-out is chosen, this MOX option for dealing with the Pu stockpile would no longer be viable.

Without establishing a complete fuel cycle with FBR, geological disposal becomes more complicated. Before the accident, the policy was to reprocess all spent nuclear fuel and to utilize separated Pu as MOX first for LWRs, but eventually for FBRs. If FBRs are deployed, the resultant wastes that require deep geological disposal are HLW and intermediate-level waste (so-called TRU waste) from reprocessing. Because only trace amounts of weapons-usable materials, such as $\mathrm{Pu}$, are included in HLW or TRU, the International Atomic Energy Agency (IAEA) would terminate its safeguards inspection for a disposal facility for these two types of waste. But, if a repository is for disposal of spent fuel (either MOX or UOX), separated Pu and U, IAEA will not terminate its safeguards inspection in perpetuity. In addition to safeguardability issues, a geological repository for spent fuels can potentially be a greater radiological risk than that for HLW and TRU.

These issues, i.e., (1) Aomori Prefecture's refusal to store HLW and spent fuel in Rokkasho without a plan for them to be taken out to a permanent geological repository, (2) drainage of national wealth for purchasing additional oil and gas, (3) international pressure on Japan not to have an unnecessary $\mathrm{Pu}$ stockpile, and (4) perpetual safeguards inspection and higher potential radiological risk to be imposed on a final repository for spent fuel and separated $\mathrm{Pu}$ and $\mathrm{U}$, are coupled to each other, creating a deadlocked situation after the accident. If reactors are back in operation and reprocessing is conducted at Rokkasho, aforementioned issues (1), (2), and (3) could be solved, but the resultant repository would require high maintenance for a long-term period. Public agreement on this scenario seems to be very difficult to reach under the current situation. If reactors restart but reprocessing is abandoned, (2) and (3) could be solved, while (1) and (4) remain unsolved. If reactors and reprocessing are decommissioned, all four issues remain unsolved, while public support for this option may be the greatest.

Open Access This chapter is distributed under the terms of the Creative Commons Attribution Noncommercial License, which permits any noncommercial use, distribution, and reproduction in any medium, provided the original author(s) and source are credited. 


\section{References}

1. Cabinet Secretariat, Japanese Government (11 Sep 2012) Status of plutonium management. Handout No. 2 distributed at the $39^{\text {th }}$ meeting of Atomic Energy Commission. Available at: http://www.aec.go.jp/jicst/NC/iinkai/teirei/siryo2012/siryo39/siryo2.pdf. Accessed 20 July 2014 (in Japanese)

2. Ministry of Finance, Japanese Government (n.d.) Trade statistics of Japan. Available at: http:// www.customs.go.jp/toukei/info/index_e.htm. Accessed 20 July 2014

3. Ministry of Economy, Trade and Industry, Japanese Government (2014) Statistics on resources and energy. Available at: http://www.meti.go.jp/statistics/tyo/sekiyuka/index.html\#menu1. Accessed 20 July 2014 (in Japanese) 